\section{International Scientific Journal Theoretical \& Applied Science}

Naima Nabikhanovna Ubaydullaeva associate professor, candidate of medical sciences, head of department

Tashkent Institute of Postgraduate Medical Education, Uzbekistan

Year: 2017 Issue: 02 Volume: 46

Published: 28.02.2017 http://T-Science.org

SECTION 20. Medicine.

\title{
TOBACCO SMOKING AS A PREDICTOR OF BRONCHIAL HYPERRESPONSIVENESS IN TEENAGERS AND YOUNG MEN
}

\begin{abstract}
There were examinated 120 young men and teenagers. Some of them are active (53 persons) and others are passive (67 persons) smokers. All patients have hyperreactivity of bronchus but only 33,3\% have bronchial obstruction. We show that active smokers' patients have early signs of chronic bronchitis, "smokers' cough" and reversible obstruction.

Key words: smokers, hyperreactivity of bronchus, bronchial obstruction.

Language: Russian

Citation: Ubaydullaeva NN (2017) TOBACCO SMOKING AS A PREDICTOR OF BRONCHIAL HYPERRESPONSIVENESS IN TEENAGERS AND YOUNG MEN. ISJ Theoretical \& Applied Science, 02 (46): 125-128.

Soi: http://s-o-i.org/1.1/TAS-02-46-23 Doi: crossef https://dx.doi.org/10.15863/TAS.2017.02.46.23

\section{ТАБАКОКУРЕНИЕ КАК ПРЕДИКТОР ГИПЕРРЕАКТИВНОСТИ БРОНХОВ У ПОДРОСТКОВ И ЮНОШЕЙ}

Аннотация: Исследовано 120 юношей и подростков. Некоторые из них являются активными (53 человека) и другие являются пассивными (67 человек) курильщиками. Все пачиенты имеют гиперреактивность бронхов, но только 33,3\% имеют бронхиальную обструкцию. Нами выявлено, что ранние признаки хронического бронхита, симптомы обратимой бронхиальной обструкции, «кашель курильщика» чаще встречались в группе активных курильщиков.
\end{abstract}

Ключевые слова: курильщики, гиперреактивность бронхов, бронхиальная обструкция.

\section{Введение}

Табакокурение является одним из агрессивных факторов риска, приводящих к раннему развитию заболеваний, несущих обществу большое социальное бремя. Широкое распространение табакокурения в различных странах мира приводит к снижению продолжительности жизни населения, что доказано многими научными исследованиями как отечественных, так и зарубежных авторов [2, с.35; 10, с. 1477]. В последние десятилетия табакокурение среди лиц подросткового возраста приобрело массовый характер, без особых различий среди лиц женского и мужского пола. По оценкам ВО3 более 150 миллионов подростков в мире употребляют табак, и это число неуклонно растет. В настоящее время около 5,4 миллиона человек умирают каждый год из-за болезней связанных с курением, которое является единственной и предотвратимой причиной смерти [3, с. 84; 9]. Прогнозируется, что цифра возрастет до 8 и более миллионов в год к 2030 году. Если тенденция сохранится, то основная масса смертей случится в развивающихся странах, где каждый год будет умирать более 7 миллионов людей в результате болезней, связанных с табаком, а это больше, чем от малярии, травматизма и условий жизни вместе взятых [5, с. 9; 8, с. 15; 11, с. 611].

Каждый пятый человек в мире - подросток, и образ жизни, привитый в юном возрасте, обязательно дает результаты в возрасте зрелом, трудоспособном. Такие привычки, как курение табака, отсутствие физической активности скажутся на формировании различных заболеваний, в том числе хронических, приводящих к ранней инвалидности, к снижению показателей функции внешнего дыхания и, как следствие, более низкой работоспособности, 
толерантности к физической нагрузке, раннему формированию хронических заболеваний органов дыхания и сердечно-сосудистой системы [1, с. 462]. Известно, что развитие зависимости к никотину наиболее быстро происходит в молодом возрасте [4, с. 111]. Поэтому основной аудиторией для активной профилактики табакокурения считают молодежь, подростков, среди которых проблема формирования зависимости к табаку приобрела в последнее десятилетие характер эпидемии [7, с. 8].

Особую опасность для детей представляет пассивное курение. Отрицательное его влияние выражается в увеличении риска развития инфекции нижних дыхательных путей (бронхит, пневмония), накопление жидкости в среднем ухе, появлении симптомов воспаления верхних дыхательных путей (кашель, мокрота, одышка), достоверным снижением функциональных показателей бронхиальной проходимости, более тяжелым течением бронхиальной астмы. Дети плохо успевают в школе, быстро утомляются, с трудом воспринимают новый материал [6, с. 148].

Целью исследования явилось изучение влияния курения табака на возникновение гиперрактивности бронхов у подростков и юношей.

\section{Материалы и методы исследования.}

В исследовании участвовали 120 подростков и юношей от 15-18 лет (учащиеся колледжей города Ташкента), в анамнезе которых отмечалось активное и пассивное курение табака.

Исследование функции внешнего дыхания проводили на аппарате «Мастерлаб» (фирмы «Ерих Егер», Германия) с анализом всех скоростных и объемных показателей. Определяли степень обструкции бронхиального дерева посредством анализа кривой поток-объем и по нарастанию бронхиального сопротивления воздушному потоку.

На следующем этапе исследования у пациентов проводилась оценка гиперреактивности бронхов с помощью недельного мониторирования пикфлоуметрии, для определения которой рассчитывался показатель суточных колебаний К:

$\mathrm{K}=((\max$ пиковая скорость выдоха за неделю - min пиковая скорость выдоха за неделю) / $\max$ пиковая скорость выдоха) х $100 \%$

Кроме того, для определения обратимости бронхиальной обструкции проводился бронхолитический тест. Бронхолитический тест считался положительным, если при его проведении FEV1 или PEF увеличивались более чем на $12 \%$.

\section{Результаты исследования и их обсуждение.}

Анализ данных опроса выявил, что лишь 53 - были активными курильщиками (44,2\%) и 67 $(55,8 \%)$ - пассивными. При этом, отягощенная наследственность была характерна для пассивных курильщиков.

Клинические проявления бронхиальной астмы были типичными у $88,2 \%$ больных, у которых наблюдались при активном курении приступы экспираторного диспноэ и кашель с трудноотделяемой вязкой мокротой, отхождение которой приводило к значительному улучшению состояния. Приступы удушья возникали преимущественно в ночное время и только у $18 \%$ - в дневное. Нами была проведена сравнительная характеристика больных бронхиальной астмой активных и пассивных курильщиков (табл.1). $83,0 \%$ активно курящих больных предъявили жалобы на кащель с выделением мокроты в утреннее время («кашель курильщика»). В случае атипичного течения у 11,8\% больных отмечено выделение мокроты без предшествующего кашля, одышка при физической нагрузке при классических приступах удушья и функционально подтвержденные признаки гиперчувствительности бронхов. У всех пациентов был выражен астено-вегетативный синдром, наблюдалось быстрая утомляемость, плаксивость нарушение сна.

При функциональном исследовании признаки обратимой бронхиальной обструкции выявлялись в $60,4 \%$ случаев у активных курильщиков, у остальных больных нарушений бронхиальной проходимости не было. У всех обследованных выявлены признаки гиперреактивности бронхов.

Как видно из приведенных данных, «кашель курильщика», наряду с обратимыми нарушениями бронхиальной проходимости достоверно чаще $(83,0 \%)$ встречался в группе активно курящих больных бронхиальной астмой, несмотря на их молодой возраст. Можно сделать вывод, что эта категория больных является непосредственной группой риска по возникновению хронической обструктивной болезни легких. 


\begin{tabular}{l|lr|ll|ll} 
& ISRA (India) & $=\mathbf{1 . 3 4 4}$ & SIS (USA) & $=\mathbf{0 . 9 1 2}$ & ICV (Poland) & $=\mathbf{6 . 6 3 0}$ \\
Impact Factor: & ISI (Dubai, UAE) $=\mathbf{0 . 8 2 9}$ & PUHI (Russia) $=\mathbf{0 . 2 3 4}$ & PIF (India) & $=\mathbf{1 . 9 4 0}$ \\
& GIF (Australia) & $=\mathbf{0 . 5 6 4}$ & ESJI (KZ) $=\mathbf{1 . 0 4 2}$ & IBI (India) & $\mathbf{4 . 2 6 0}$
\end{tabular}

Таблица 1

Сравнительная характеристика больных бронхиальной астмой - активных и пассивных курильщиков

\begin{tabular}{|c||c||c||c||c|c||}
\hline $\begin{array}{c}\text { Характер } \\
\text { курения }\end{array}$ & $\begin{array}{c}\text { Количество } \\
\text { больных }\end{array}$ & $\begin{array}{c}\text { «Кашель } \\
\text { курильщика» }\end{array}$ & $\begin{array}{c}\text { Отягощенная } \\
\text { наследствен- } \\
\text { ность }\end{array}$ & $\begin{array}{c}\text { Более 4-х } \\
\text { приступов } \\
\text { удушья в сутки }\end{array}$ & $\begin{array}{c}\text { Обратимые } \\
\text { нарушения } \\
\text { бронхиальной } \\
\text { проходимости }\end{array}$ \\
\hline Активное & 106 & $88(83,0 \%)^{*}$ & $54(50,9 \%)^{*}$ & $36(34,0 \%)$ & $64(60,4 \%)^{*}$ \\
\hline \hline Пассивное & 144 & $24(15,6 \%)$ & $122(79,2 \%)$ & $48(31,2 \%)$ & $16(10,4 \%)$ \\
\hline
\end{tabular}

Примечание. *- достоверные различия $(p<0,05)$ между группой активных и пассивных курильщиков, страдающих бронхиальной астмой..

Параметр пиковой скорости выдоха был достоверно выше у условно здоровых, по сравнению с пассивными курильщиками $(\mathrm{p}<0,0001)$, а также по сравнению с активными курильщиками $\quad(\mathrm{p}<0,0005)$. $\quad$ У $\quad$ активных курильщиков с симптомами бронхиальной астмы параметр пиковой скорости выдоха был также достоверно ниже, чем у курящих, не имеющих нарушений бронхиальной проходимости.

Специфические противовоспалительные препараты принимали лишь $25 \%$ больных молодого возраста, остальные прибегали к симптоматической бронхолитической терапии (препараты из группы теофиллинов, симпатомиметики), практически никто не принимал отхаркивающие средства.

\section{Выводы.}

1. Лица молодого возраста, страдающие бронхиальной астмой, чаще являются пассивными курильщиками, при этом для них характерна отягощенная наследственность .

2. Тяжесть течения бронхиальной астмы у лиц молодого возраста зависит от характера курения. Категория активно курящих больных бронхиальной астмой является непосредственной группой риска по возникновению хронической обструктивной болезни легких.

3. Косвенные признаки хронического бронхита - симптомы обратимой бронхиальной обструкции, «кашель курильщика», достоверно чаще встречались в группе активных курильщиков, у которых отмечалось снижение пиковой скорости выдоха.

\section{References:}

1. Andreev PM, Latipov AG (1994) Sostoyaniye functii vnesnego dikhaniya u podrostkov // P.M.Andreev, A.G.Latipov / Kazanskiy medicinskiy jurnal, T. IXXV, № 6, pp. 461462.

2. Babanov SA (2002) Epidemiologiya I profilaktika tabakokureniya // S.A.Babanov / Gigiena I sanitariya, № 3, pp. 33-36.

3. Golub NI (1992) Vliyanie tabakokureniya na immunnuyu I nespecificheskuyu resistentnost // N.I.Golub / Pulmonologiya, №1, pp. 83-86.

4. Gurova OA, Samburova IP, Sokolov EV (1991) Vliyanie kureniya tabaka na organism podrostkov // O.A.Gurova, I.P.Samburova, E.V.Sokolov / Novie issledovaniya v psihologii I vozrastnoy fiziologii, № 2, pp. 110-112.

5. Kamardina TV, Glazunov IS, Sokolova LA (2002) Rasprostranennost kureniya sredi jenshin Rossii // T.V.Kamardina, I.S. Glazunov, L.A. Sokolova / Profikaktika zabolevaniy i ukrepleniye zdorovya, № 1, pp. 7-12.

6. Levashova IA, Chayka AN, Adelshina AA (2002) Sostoyaniye zdorovya shkolnikov I rasprostranennost sredi nih kureniya // Materiali кonferencii «Aktualniye voprosi obespecheniya sanitarno-epidemiologicheskogo 


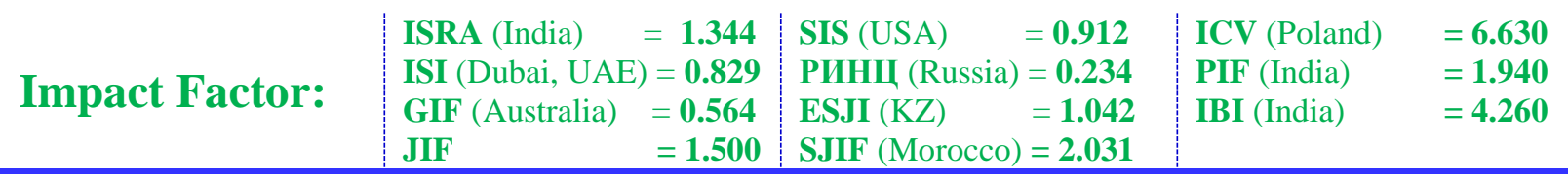

blagopoluchiya i okhrani zdorovya centralnogo regiona Rossii, Smolensk, pp. 147-149.

7. Sapunova NO (2005) gigienicheskoe obosnovaniye programmi profilaktiki i okhrani zdorovya shkolnikov $\mathrm{v}$ ramkah proekta "Zdorovue goroda": avtoref.diss. ...kand.med.nauk, Moscow, 18 p.

8. Skvorcova ES (1996) Rasprostranennost I motivi kureniya sredi gorodskih podrostkovsholnikov RF // E.S.Skvorcova / Rossiyskiy medicinskiy jurnal, № 6, pp. 14-17.
9. Federal U.S. Agency for integrated prevention and control of tobacco addiction and smoking / http://www.cdc.gov/tobacco/global/gyts/ (Date of access: 26.03.2010).

10. Chuchalin AG (2008) Tabakokureniye I bolezni organov dikhaniya // A.G.Chuchalin / Rossiyskiy medicinskiy jurnal, № 22, pp. 1477.

11. Shibochkina EI, Molchanova SS, Kulikova AV (2005) Kuryashie podrostki kak medicosocialnaya problema // Materiali syezda pediatrov Rossii, Moscow, pp. 611. 